\title{
Primary cutaneous mucormycosis of the scalp
}

Bommie Florence Seo ${ }^{1}$, Jeong Hwa Seo ${ }^{1}$, Gyeol Yoo $^{2}$

${ }^{1}$ Department of Plastic and Reconstructive Surgery, Uijeongbu St. Mary's Hospital, College of Medicine, The Catholic University of Korea, Seoul; ${ }^{2}$ Department of Plastic and Reconstructive Surgery, Incheon St. Mary's Hospital, College of Medicine, The Catholic University of Korea, Seoul, Korea

Correspondence: Gyeol Yoo

Department of Plastic and Reconstructive Surgery, Incheon St. Mary's Hospital, College of Medicine, The Catholic University of Korea, 56 Dongsu-ro, Bupyeong-gu, Incheon 21431, Korea

Tel: +82-32-280-5184, Fax: +82-32-510-2370, E-mail: psyg@ @atholic.ac.kr

Received: June 22, 2020 • Revised: July 8, 2021 • Accepted: July 23, 2021 pISSN: 2234-6163 • elSSN: 2234-6171

https://doi.org/10.5999/aps.2020.01340 • Arch Plast Surg 2021;48:526-527 Copyright (C) 2021 The Korean Society of Plastic and Reconstructive Surgeons This is an Open Access article distributed under the terms of the Creative Commons Attribution Non-Commercial License (https://creativecommons.org/licenses/by-nc/4.0/) which permits unrestricted non-commercial use, distribution, and reproduction in any medium, provided the original work is properly cited.

Mucormycosis is a fungal infection caused by the Zygomycetes class and genus of Mucorales, which usually reside in soil or plants. While daily exposure is common, infection has only been reported in immunocompromised patients. Because the route of exposure is usually fungal spores via air, human mucormycosis usually occurs in the form of pulmonary or rhinocerebral infections. Primary cutaneous mucormycosis is a rare form of the entity, reported to have rapid progression and high mortality. An 83-year-old male who had finished his sixth cycle of chemotherapy for small cell lung cancer, presented with pus-like discharge from two openings on the scalp and swelling of his left periorbital region, with chemosis of his conjunctiva and decreased ocular motility in all directions but no diplopia (Fig. 1).

Magnetic resonance imaging showed myositis of the superior rectus muscle and optic neuritis, but no brain involvement (Fig. 2). Wound cultures were negative for microorganisms and there was no significant response to intravenous antibiotics or debridement. A biopsy was performed and histopathology revealed thick-walled non-septate hyphae, with irregular wide-angle branches, consistent with the diagnosis of primary cutaneous mucormycosis (Figs. 3, 4). We immediately
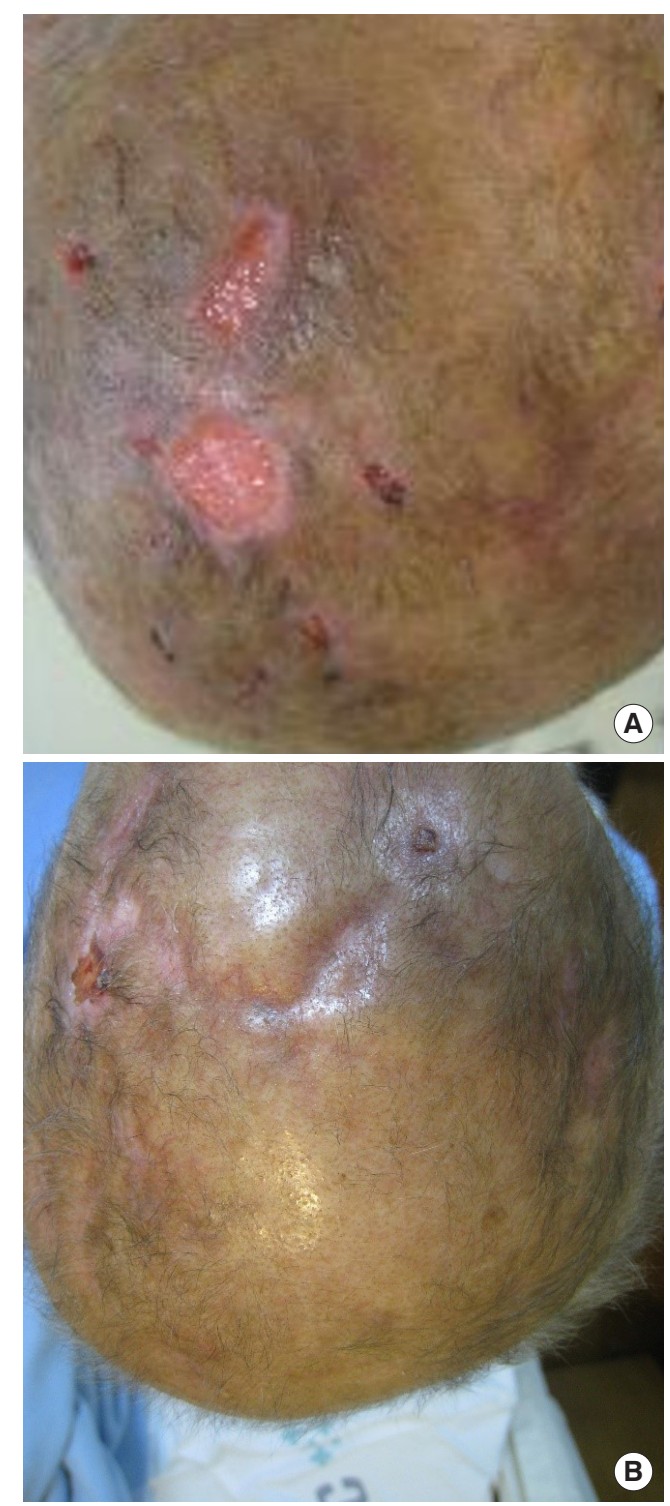

Fig. 1.

Clinical photographs of patient's scalp. (A) Before any treatment. (B) After wound care of suturing and negative pressure wound therapy, healthy granulation tissue and no complication of scalp lesion.

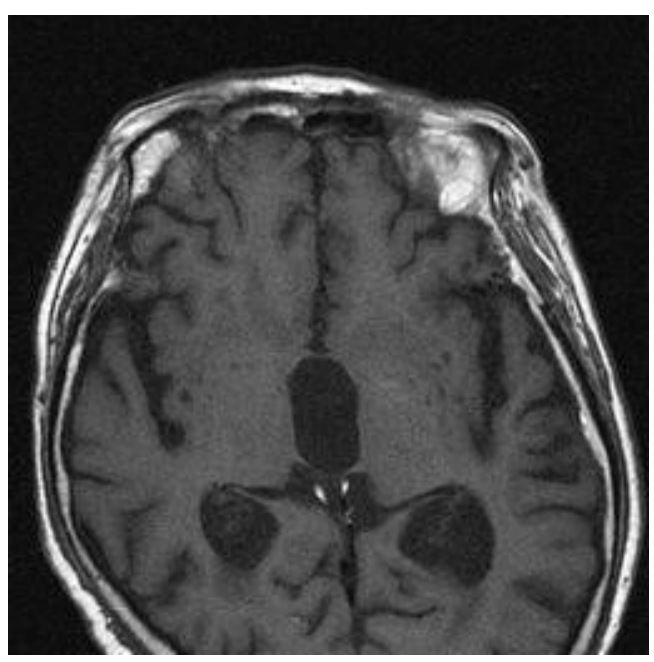

Fig. 2.

Magnetic resonance imaging image of the time of periorbital swelling, which shows no involvement to brain and mucormycosis is just cutaneous layer. 


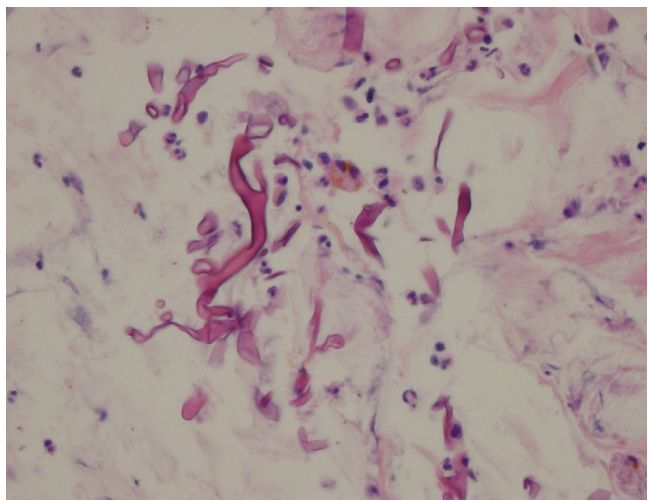

Fig. 3. Pathological diagnosis of the non-septated, greater angle of hyphae means mucormycosis $(\mathrm{H} \& \mathrm{E}, \times 200)$.

administered systemic amphotericin B ( $1 \mathrm{mg} / \mathrm{kg} /$ day $)$ and his wounds and the orbital lesion healed rapidly within 20 days. Primary cutaneous mucormycosis occurs uncommonly, and is usually caused by direct inoculation by fungal spores into the skin in immunocompromised patients. Intravenous amphotericin B is an effective first-line therapy. While the presentation of cutaneous mucormycosis may resemble cellulitis or cutaneous abscesses of variable causes, the physician should have a high degree of suspicion for early diagnosis and proper, effective treatment.

\section{NOTES}

\section{Conflict of interest}

No potential conflict of interest relevant to this article was reported.

\section{Ethical approval}

The study was approved by the Institutional Review

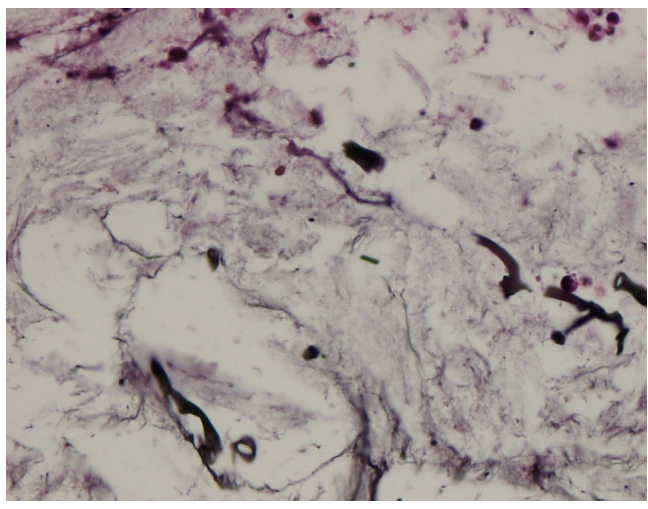

Fig. 4. After wound care, histopathology showing healthy granulation tissue formation without remnant hyphae (silver staining, $\times 200$ ).

Board of the Catholic Medical Center (IRB No.

OC20ZISI0012) and performed in accordance with the principles of the Declaration of Helsinki. Written informed consent was obtained.

\section{Patient consent}

The patient provided written informed consent for the publication and the use of his images.

\section{Author contribution}

Conceptualization: BF Seo. Data curation: JH Seo.

Formal analysis: JH Seo. Methodology: G Yoo.

Visualization: JH Seo. Writing - original draft: BF Seo. Writing - review \& editing: G Yoo.

\section{ORCID}

Bommie Florence Seo https://orcid.org/0000-0002-6907-5962 Jeong Hwa Seo https://orcid.org/0000-0002-0911-4747

Gyeol Yoo https://orcid.org/0000-0002-1029-8643 